\title{
Modeling the Influence of River Cross-Section Data on a River Stage Using a Two-Dimensional/ Three-Dimensional Hydrodynamic Model
}

\author{
Wei-Bo Chen ${ }^{1}$ and Wen-Cheng Liu ${ }^{2, *}$ \\ 1 National Science and Technology Center for Disaster Reduction, New Taipei City 23143, Taiwan; \\ wbchen@livemail.tw \\ 2 Department of Civil Disaster Prevention Engineering, National United University, Miaoli 36063, Taiwan \\ * Correspondence: wcliu@nuu.edu.tw; Tel.: +886-37-382357
}

Academic Editor: Karl-Erich Lindenschmidt

Received: 10 November 2016; Accepted: 8 March 2017; Published: 10 March 2017

\begin{abstract}
A large amount of accurate river cross-section data is indispensable for predicting river stages. However, the measured river cross-section data are usually sparse in the transverse direction at each cross-section as well as in the longitudinal direction along the river channel. This study presents three algorithms to resample the river cross-section data points in both the transverse and longitudinal directions from the original data. A two-dimensional (2D) high-resolution unstructured-grid hydrodynamic model was used to assess the performance of the original and resampled cross-section data on a simulated river stage under low flow and high flow conditions. The simulated river stages are significantly improved using the resampled cross-section data based on the linear interpolation in the tidal river and non-tidal river segments. The resampled cross-section data based on the linear interpolation satisfactorily maintains the topographic and morphological features of the river channel, especially in the meandering river segment. Furthermore, the performance of the 2D and three-dimensional (3D) models on the simulated river stage was also evaluated using the resampled cross-section data. The results indicate that the $2 \mathrm{D}$ and $3 \mathrm{D}$ models reproduce similar river stages in both tidal and non-tidal river segments under the low flow condition. However, the 2D model overestimates the river stages in both the tidal and non-tidal river segments compared to the 3D model under the high flow condition. The model sensitivity was implemented to investigate the influence of bottom drag coefficient and vertical eddy viscosity on river stage using 2D and 3D models based on the linear interpolation method to resample river bed cross-section. The results reveal that the change of bottom drag coefficient has a minor impact on river stage, but the change of vertical eddy viscosity is insensitive to river stage.
\end{abstract}

Keywords: river bed bathymetry; cross-section; river stage; resample; hydrodynamic model; 2D/3D

\section{Introduction}

A growth in population and economic activities near rivers has caused an increased flood risk to many urban regions. More reliable and integrated computer models are needed to help identify and assess appropriate flood risk management measures. Traditionally, one-dimensional (1D) hydrodynamic models have been widely used in modeling river stages and flood flows because of their low computational cost and the relatively scare field data that they require. These types of models are computationally efficient for dealing with large and complex river/channel systems as well as various hydraulic structures such as bridge pier and weir. However, when modeling river stages and floodplain flows, the accuracy and appropriateness of a 1D model is insufficient [1,2]. These kinds of 1D models are unable to represent the actual meandering river shape [3]. Merwade et al. [4] 
summarized the limitations of a 1D hydrodynamic model, which was not capable of representing detailed river bathymetry and topography or stimulating hydrodynamic conditions during large scale extreme events and complex river systems. Therefore, the use of two-dimensional/three-dimensional (2D/3D) models becomes necessary [5,6].

Although much progress has been made in the representation and simulation of river processes in $2 \mathrm{D} / 3 \mathrm{D}$, the successful application of these models is directly linked to accurate bathymetric representation [7]. Bathymetric data are incorporated into 2D/3D models by interpolating the observed cross-sections to obtain the elevations at the model nodes of a finite element mesh. Many studies have used also spatially continuous bathymetric data for model simulations [8-10]. Therefore, the accuracy of the bathymetric surfaces represented in 2D/3D models is dependent on the ability of the interpolation methods to make accurate predictions at unmeasured locations using discrete data. There are several interpolation methods that have been used, such as triangulation, inverse distance weighting (IDW), splines, and Kriging [4,11,12]. They are the most common spatial prediction techniques and have many advantages. For instance, the ready-made codes can easily be used on any other computers. However, if the strong anisotropy exists in the measured river cross-section data of river channels, it is difficult to predict the river topography using those methods [13]. Caviedes-Voullieme et al. [3] presented an algorithm to generate the missing information for the areas between cross-sections. The algorithm produced a river bed that preserved important morphological features of a river, but the algorithm needs to define a cubic Hermite spline. A cubic Hermite spline is a spline with Hermite form third-degree polynomial in each piece by its values and first derivatives at the endpoints of the interpolation interval (i.e., river cross-section).

A large amount of bathymetric and topographic data is a primary requirement for $2 \mathrm{D} / 3 \mathrm{D}$ water stage simulation $[3,7,14,15]$. An adequate interpolation method is also indispensable need to make accurate predictions at unmeasured locations using discrete data. Beside, hypsometry techniques to generate such as Digital Terrain Data (DTM) are important for river stage and sediment transport morphodynamic modeling. The LiDAR techniques have widely been used to describe the dry areas of rives except the regions covered by water $[8,16]$. Airbone LiDAR techniques also have limitations for measurements of terrain under water [17]. The traditional bathymetry surveys or SONAR techniques [18] are alternative solutions for obtaining the measured river cross sections data. However it is difficult to obtain high accuracy bathymetric and topographic data for a river bed [3]. This study presents several simple approaches to refine the sparse measured cross sections of a river bed.

Most of the researchers focused on developing an algorithm that interpolated sparse measurements of river cross-section to produce a smooth river bathymetry for use in flow modeling $[3,4,12,19,20]$. In the present study, three algorithms including linear interpolation, inverse distance weighting (IDW), and natural neighbor $(\mathrm{NN})$ were presented to resample the river cross-sectional data in both the transverse and longitudinal directions from the originally measured data points. The 2D model was adopted to compare the simulated and observed water sages using original data and resampled cross-section data with different algorithms. The 3D hydrodynamic models were then used to simulate river stages using the resampled river bed cross-section data based on linear interpolation method under the low flow and high flow conditions in the Tsengwen River of northern Taiwan. The simulated results with original and different resampled river bed cross-sectional data were presented. Then, sensitivity analyses regarding the bottom drag coefficient and vertical eddy viscosity were investigated using 2D and 3D models based on the linear interpolation method to resample river bed cross-section and, finally, conclusions were drawn.

\section{Description of Study Area}

The Tsengwen River is the second largest river in Taiwan and drains into the southern Taiwan Strait (Figure 1). The drainage basin has an area of $1177 \mathrm{~km}^{2}$, which includes part of the southwestern rugged foothills and fertile coastal plains. The tide is the primary tidal constituent at the river mouth 
and has a mean tidal range below $1 \mathrm{~m}$. Based on the tidal classification [21], the Tsengwen River mouth can be classified as a microtidal estuary [22,23]. The average annual rainfall for the drainage basin is $2643 \mathrm{~mm}$, with a contrasting rainfall pattern between dry and wet seasons. The dry and wet seasons are October-April and May-September, respectively. Thus, the river discharge varies seasonally with a high discharge of $411 \times 10^{3} \mathrm{~m}^{3} /$ day in the wet season and a low discharge of $14 \times 10^{3} \mathrm{~m}^{3} /$ day in the dry season. In the wet season, episodic flooding from heavy monsoon rains and typhoons is not unusual and critically affects the river discharge and the suspended load.

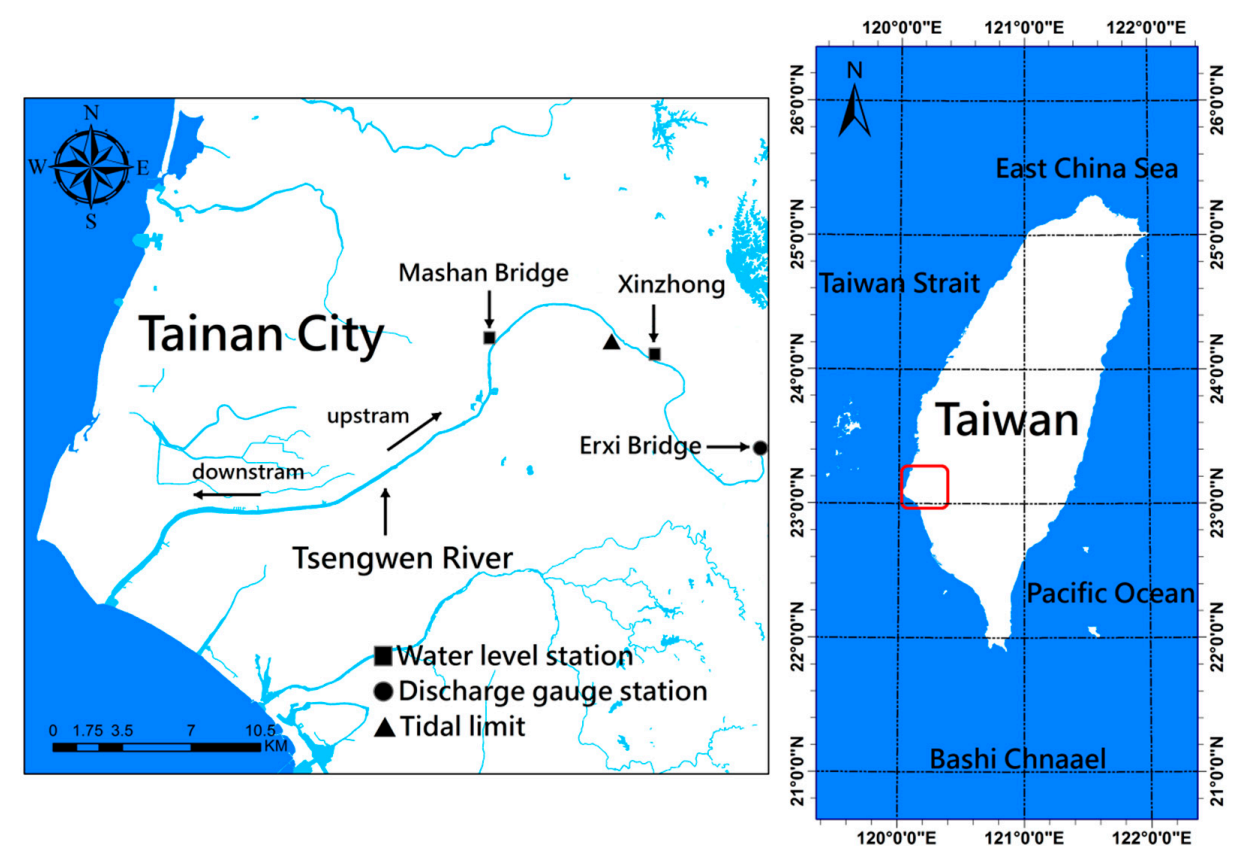

Figure 1. Maps of the study area (white, blue, and cyan represent land, ocean, and river, respectively).

\section{Materials and Methods}

\subsection{Methods for Resampling River Cross-Section Data}

The 2D/3D numerical simulation of the water stage and river flow requires a large amount of topographic data to build an accurate finite element mesh. The cross-sectional data were measured in 2012 at every 500-890 m interval that was collected from the Water Resources Agency, Taiwan. To obtain fine cross-section data for grid generation, a resampling the original cross-section was necessary. In the present study, three interpolation approaches (i.e., linear interpolation, IDW, and NN) are adopted to resample the cross-sectional data from the original sample.

The algorithm is composed of four steps. The first step is to find the lowest point and the maximal slope point of the lowest point from each original cross-section for the left and right banks. Each cross section is divided into four parts, including the left bank, main channel $\mathrm{L}$, main channel $\mathrm{R}$, and right bank (shown in Figure 2). The second step is to redistribute the number of cross-sectional data points based on these four parts and to use interpolation method in the transverse direction along each original cross section to yield the elevation of each new cross-sectional data point. The third step is to generate the extra cross sections and data points between each pair of original cross sections in the longitudinal direction using interpolation method. Therefore, each part at each cross section has an equal number of points. Finally, the interpolation method is conducted to obtain the elevation between the corresponding parts of each cross section. After resampling, the new cross-section data set contains the refined cross section with an equal number of the data points. The quality of resampled cross-section data is highly dependent on number of original data points. The interpolation algorithm used in the present study is similar to the algorithm developed by Caviedes-Voullieme et al. [3]. 
They also found that the well located cross-sections data are the most important requirement for interpolating the high quality river bed. Besides, they concluded that automatic treats the void and overlapping regions between floodplain and river bed topography as well as confluences and islands are still needed to be improved.

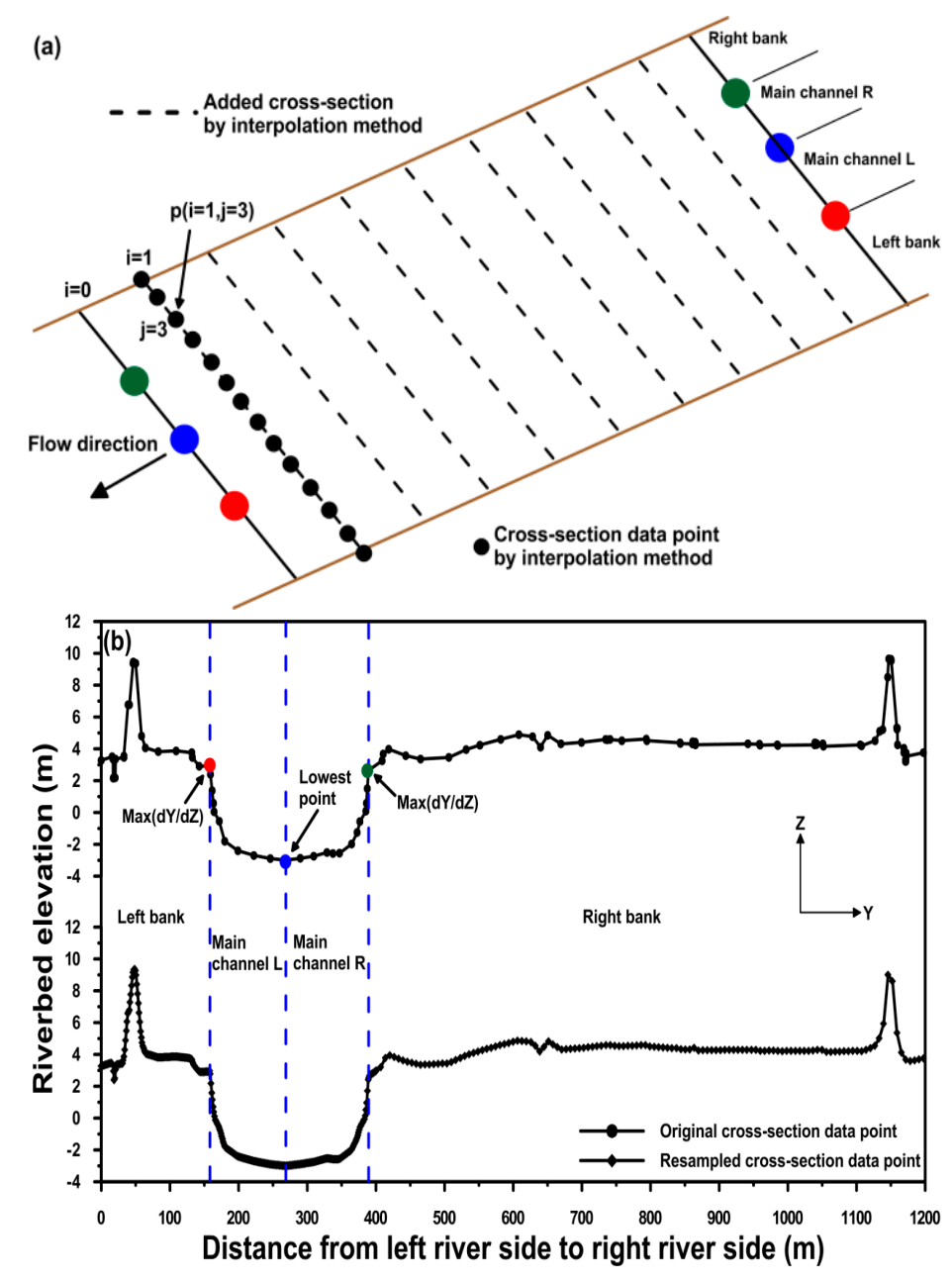

Figure 2. (a) Conceptual diagram of the resampling method (L and $\mathrm{R}$ represent the main channel at left part and right part); and (b) comparison of the original and resampled cross-sectional data points generated by the linear interpolation method.

In the case of the Tsengwen River, we added an extra 10 cross sections between each pair of the original cross sections and redistributed 150 points at the left part of main channel and right part of main channel as well as 200 points at the left bank part and right bank part (see Figure 2a). Figure 2a shows a conceptual diagram of the resampling method. Figure $2 b$ depicts the resampled cross-sectional data points generated by the linear interpolation method, which satisfactorily maintains the topographic features of the original sample. After resampling, the maximal distance for each cross section is reduced from $890 \mathrm{~m}$ to $80 \mathrm{~m}$. The maximal distance for each data point at the same cross section is reduced from $150 \mathrm{~m}$ to $6 \mathrm{~m}$.

\subsection{Interpolation Methods}

\subsubsection{Linear Interpolation}

The linear interpolation is a common method used to predict the unknown values between two endpoints or to lines. The formula of linear interpolation can be described as: 


$$
P_{e}(x, y)=P_{e}\left(x_{0}, y_{0}\right)+\frac{P_{e}\left(x_{n}, y_{n}\right)-P_{e}\left(x_{0}, y_{0}\right)}{d_{t}} d_{i}
$$

where $P_{e}(x, y)$ is the estimated value at $(x, y) ; P_{e}\left(x_{0}, y_{0}\right)$ is the measured data at 0th cross-section; $P_{e}\left(x_{n}, y_{n}\right)$ is the measured data at nth cross-section; $d_{t}$ is the total distance between two cross-sections; and $d_{i}$ is the distance between $P_{e}\left(x_{0}, y_{0}\right)$ and $P_{e}(x, y)$. It should be noted that linear interpolation can avoid the artificial local maximum and minimum [3].

\subsubsection{Inverse Distance Weighting (IDW)}

The IDW interpolation is a deterministic, nonlinear interpolation technique. This method uses a weighted average of the attribute values from nearby sample points to estimate the magnitude of that attribute at non-sampled locations. The weight of any known point is set inversely proportional to its distance from the estimated point [24]. The equation for the IDW interpolation in a two-dimensional plane is given as:

$$
P_{e}(x, y)=\frac{\sum_{i=1}^{n} p_{m}(x, y)}{\sum_{i=1}^{n} \frac{1}{d_{i}}}
$$

where $p_{m}(x, y)$ is the measured data point.

\subsubsection{Natural Neighbor (NN)}

The NN interpolation is a method of spatial interpolation which was developed by Sibson [25]. This method is based on Voronoi tessellation of a discrete set of spatial points and is quite popular in many fields. The NN interpolation is a weighted moving average technique that uses geometric relationships in order to choose and weight nearby points. The equation for the NN interpolation in a two-dimensional plane is:

$$
P_{e}(x, y)=\sum_{i=1}^{n} w_{i} p_{m}(x, y)
$$

where $w_{i}$ is the weight depended on the area about each of the data points (i.e., Voronoi polygons).

\subsection{Three-Dimensional (3D) Hydrodynamic Model}

To compare the performance of simulating the river stages using original and resampled river bed cross-section data, a two-dimensional semi-implicit Eulerian-Lagrangian finite element model, SELFE-2D, was implemented to calculate the river stages in the Tsengwen River. Moreover, the three-dimensional version of SELFE was employed to compare the simulated river stages with the SELFE-2D modeling results.

SELFE-3D solves the three-dimensional shallow-water equations with the hydrostatic and Boussinesq approximations to obtain the river stages and the three-dimensional water velocities. The barotropic mode, representing a fluid whose density is a function of pressure only, is only used to predict the river stages. The tides at the river mouth and the discharge hydrographs upstream are the driving forces in the model. The governing equations of SELFE-3D can be found in Zhang and Baptista [26] and are shown in Appendix A.

\subsection{Two-Dimensional (2D) Hydrodynamic Model}

All variables used in the SELFE-3D model (see Appendix A) become depth-averaged applied in the SELFE-2D model, and this model only deals with the barotropic mode. The two-dimensional version of SELFE solves the depth-integrated momentum and continuity equations. The governing equations of SELFE-2D can be found in Zhang et al. [27] and Zhang et al. [28] and are shown in Appendix B. In the SELFE model (SELFE-2D and SELFE-3D), unstructured triangular grids are used in the horizontal direction [26]. 


\subsection{Model Implementation}

The distribution of the river bed elevation for the original cross-section data is shown in Figure 3. The river bed elevation is low at the downstream reaches, while is high at the upstream. The elevation at the upstream reaches $20 \mathrm{~m}$. Triangle unstructured meshes with a resolution of approximately $20 \mathrm{~m}$ are deployed from the Tsengwen River mouth to the Erxi Bridge, which is the location of the discharge gauge station. Figure 4 shows the triangular unstructured meshes for the entire model domain. The insert of Figure 4 focuses on the vicinity of the Tsengwen River's mouth to see the triangle meshes more clearly. The model grid consists of 259,567 elements and 132,136 nodes in the horizontal plane. Once the model meshes are generated, the different interpolation methods are adopted for interpolating the cross-sectional data to each grid.

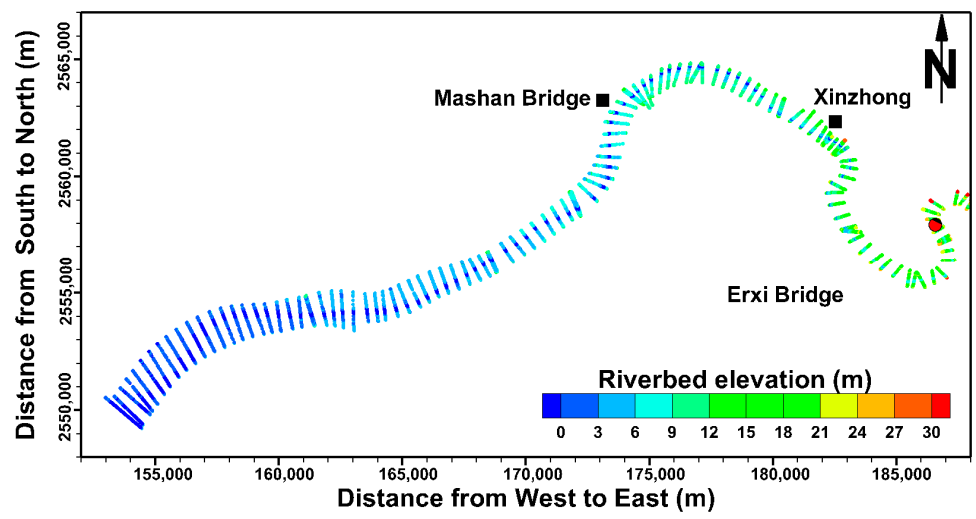

Figure 3. Distribution of the river bed elevation for the original cross section.

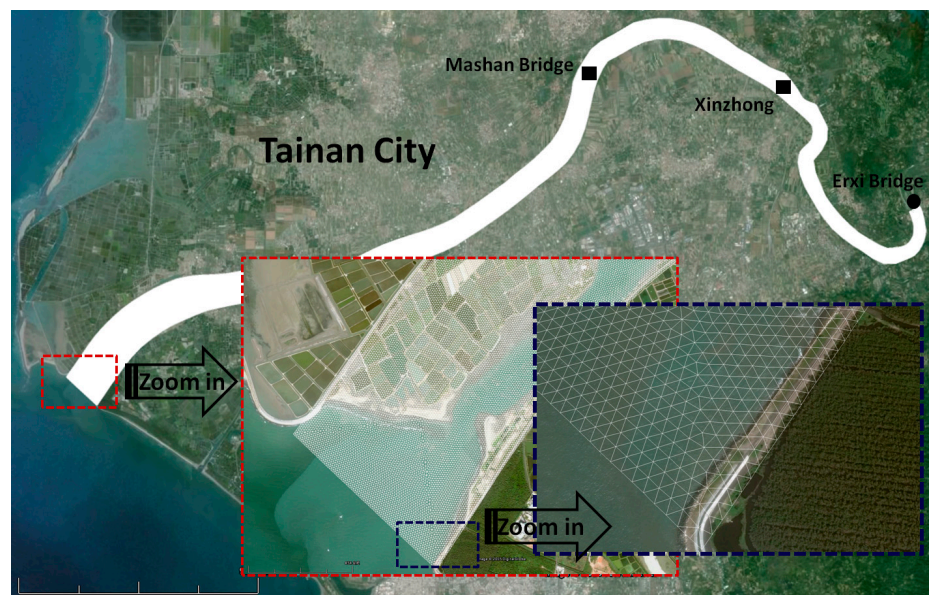

Figure 4. High resolution unstructured grids in the Tsengwen River for hydrodynamic modeling.

Juez et al. [29] simulated the granular flow over irregular steeps lopes using a finite volume numerical model. They found only the triangular unstructured meshes avoided the misleading preference directions of flood propagation. Langendoen et al. [30] generated the triangular unstructured meshes using the open source software and adapted the planar straight line graph for modeling the morphodynamics of rivers with steep banks. They pointed out that the triangular unstructured mesh with updated planar straight line graph could tackle accurately the morphological diversity in the riverbanks. Therefore the numerical model with triangular unstructured meshes was adopted in the present study for modeling water stage.

The river bed elevations were interpolated from the original cross-section data and resampled in the cross-section data using different interpolation methods shown in Figure 5. The resampled river 
cross-section data produce a similar river topography to the original river cross-section data in the straight river segments of the Tsengwen River. However, the resampled river cross-section data using the liner interpolation method (Figure $5 b$ ) generate more smooth topography and continuous thalweg trajectory in the meandering river segment of the Tsengwen River than using the original cross-section data (Figure 5a) and the IDW and NN methods (Figure 5c,d). The 3D views of the meandering segment of the Tsengwen River are illustrated in Figure 6. The rugged river bed can be found in Figure 6a,c,d. However, the river bed shows a smoothing pattern at the same river segment (Figure 6b).
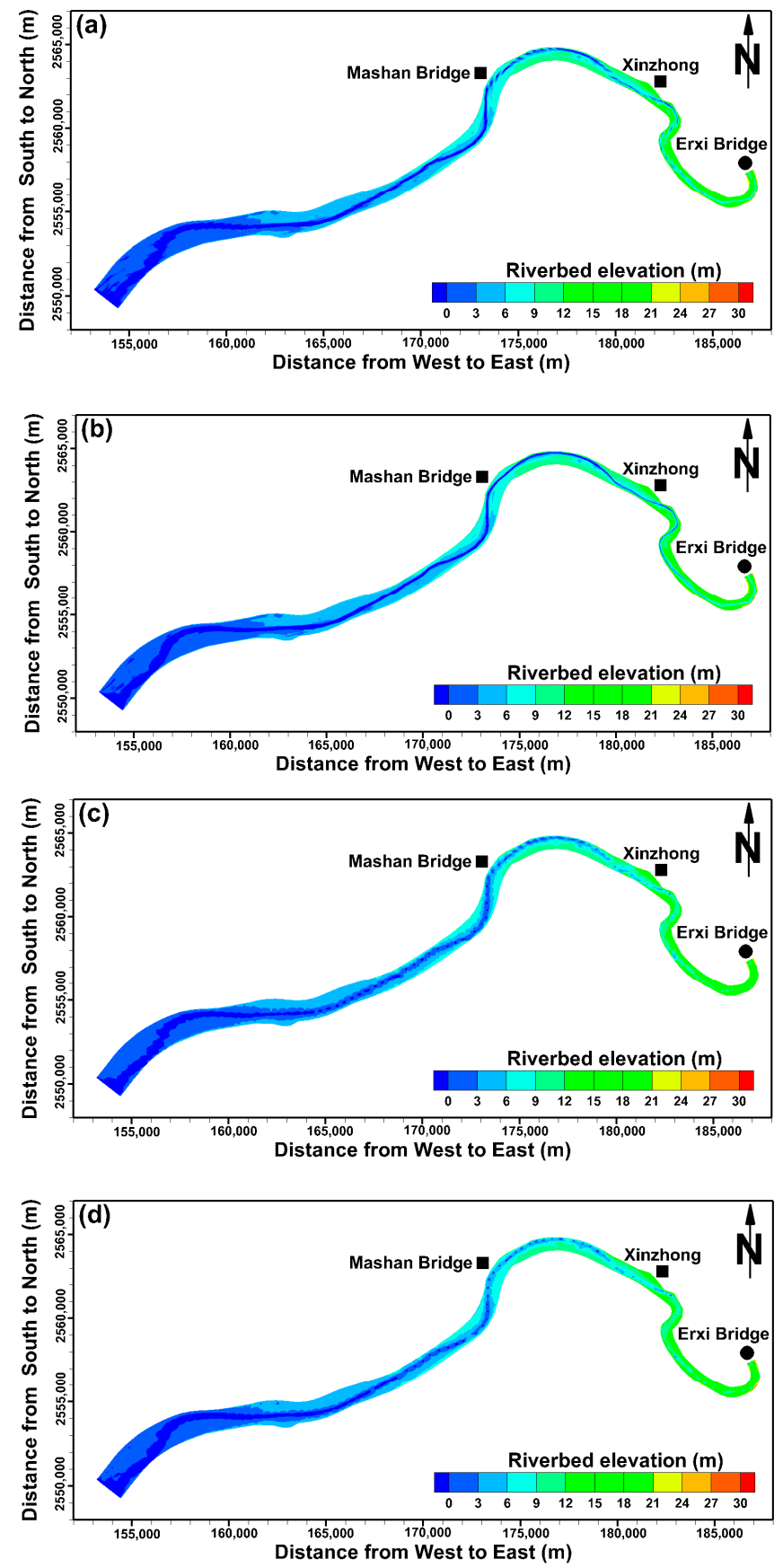

Figure 5. River bed elevation used for hydrodynamic modeling: (a) original cross-sectional data; and resampled cross-section data using: (b) the interpolation method; (c) the inverse distance weighting (IDW) method; and (d) the natural neighbor (NN) method. 

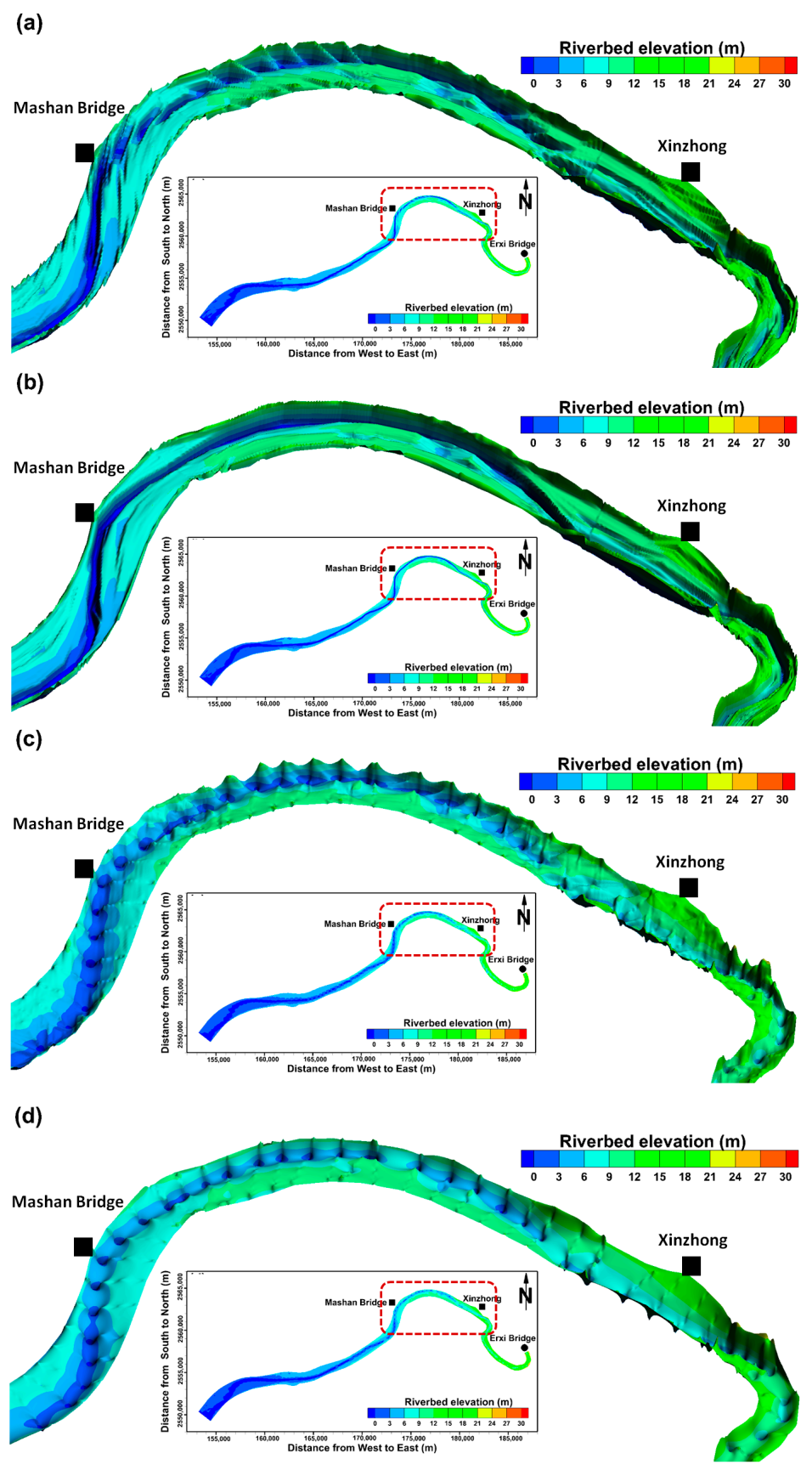

Figure 6. A 3D view of the river bed elevation of the hydrodynamic model using: (a) the original data; and resampled data according to: (b) the linear interpolation method; (c) the IDW method; and (d) the $\mathrm{NN}$ method. The red dashed box in the sub-figure represents the location of the 3D view river segment in the Tsengwen River.

Two data sets of hourly discharge hydrographs collected from the Water Resources Agency, Taiwan were extracted and imposed on the upstream boundary condition at the Erxi Bridge (a distance of $50 \mathrm{~km}$ from the Tsengwen River's mouth). One period is from 2 June to 6 June 2012 (i.e., low flow condition), and the other one is from 11 June to 16 June 2012 (i.e., high flow condition). The tidal elevations at the Tsengwen River's mouth were calculated using the regional tidal prediction model of the South China Sea [31], which served as the downstream boundary condition. The measured river stage data also collected from the Water Resources Agency, Taiwan were used to evaluate the performance on the simulation of the river stage using original and resampled river cross-section 
data. Thus, the most suitable algorithm to resample river cross-section data for simulating river stages in the Tsengwen River can be determined. The initial conditions of the water surface are set equal to the riverbed elevations. A minimum depth of $0.01 \mathrm{~m}$ was indicated as a criterion for the wetting and drying simulation. A time step of 10 seconds was used in the simulation without any signs of numerical instability.

\subsection{Assessment of the Model Performance}

To assess the model performance using different river cross-sectional data for simulating the river stages, three criteria are adopted: the mean absolute error (MAE), the root mean square error (RMSE), and the percent bias (PBIAS). The equations for these three criteria are as follows:

$$
\begin{aligned}
M A E & =\frac{1}{N} \sum_{i=1}^{N}\left|\eta_{i}^{\varsigma}-\eta_{i}^{m}\right| \\
R M S E & =\sqrt{\frac{1}{N} \sum_{i=1}^{N}\left(\eta_{i}^{s}-\eta_{i}^{m}\right)^{2}} \\
\text { PBIAS } & =\frac{\sum_{i=1}^{n} \eta_{i}^{\varsigma}-\eta_{i}^{m}}{\sum_{i=1}^{n} \eta_{i}^{m}} \times 100
\end{aligned}
$$

where $\eta_{i}^{s}$ is simulated river stage and $\eta_{i}^{m}$ is measured river stage.

\section{Results}

\subsection{Simulation of the River Stage Using Different Cross-Section Data}

Figure 7 shows the model-data comparison of the river stages at the Mashan Bridge under low flow conditions using the 2D model with the original (Figure 7a) and resampled cross-section data (Figure $7 \mathrm{~b}, \mathrm{c}, \mathrm{d}$ ). This figure includes the information of the river flow at the upper panel, the river stage at the middle panel, and the error between simulated and observed river stages at the lower panel. Because the Mashan Bridge is located at the tidal river reach of the Tsengwen River, Figure 7 reflects the river stage variations affected by flood and ebb tides. The simulated river stage using the original cross-section data (Figure 7a) shows smaller amplitudes than the resampled cross-section data using the linear interpolation method (Figure $7 \mathrm{~b}$ ). This result means that the tidal wave has slight difficulty reaching upstream if the original cross-section data are used for model simulation. The simulated river stages using the resampled cross-section data according to the IDW and NN interpolation methods show straight line with time (Figure 7c,d). It means that the simulated river stage is not affected by tide at the Mashan Bridge. The simulated river stages are quite different with the measured results.

The blocked phenomenon of the river channel is shown at the Xinzhong station using the original cross-section data (Figure 8a). Figure 8a shows that the riverbed cannot become wet at the Xinzhong station until 1:00 on 5 June 2012, and Figure $8 \mathrm{~b}$ reveals the consistency between the simulated and observed river stages using the resampled cross-section data (i.e., linear interpolation method). The simulated river stages extremely overestimate the measured river stage using the resampled cross-section data according to the IDW and NN methods (Figure 8c,d). Figure 9 presents the distribution of the simulated river stages in the Tsengwen River using the original and different resampled cross-section data. The river stages show discontinuity between the Mashan Bridge and the Xinzhong station, which is a meandering river reach of the Tsengwen River (Figure 9a,c,d). The figure also shows that the river stages are abnormally high upstream of the Xinzhong station (Figure 9a,c,d) compared to the simulated results in Figure 9b. 

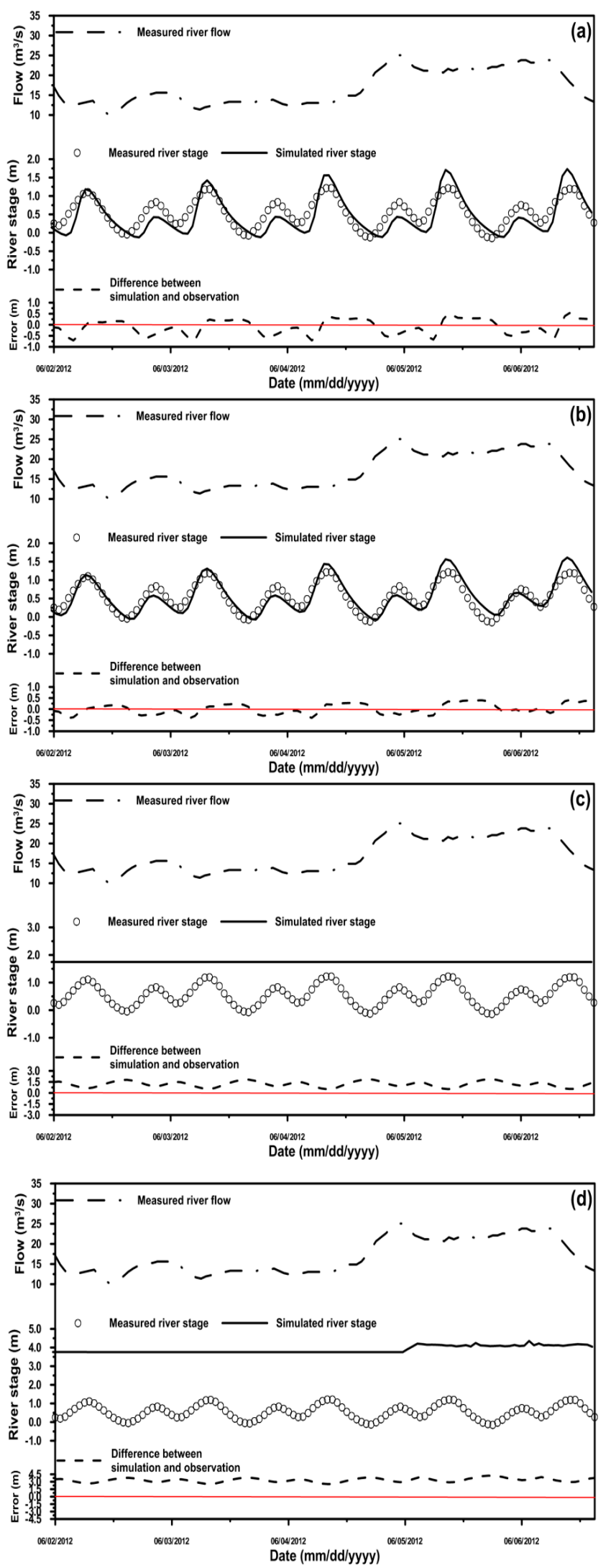

Figure 7. A comparison of the simulated and observed river stages at the Mashan Bridge under the low flow condition using the 2D model with the: (a) original cross-section data; and resampled cross-section data according to: (b) the linear interpolation method; (c) the IDW method; and (d) the NN method. 

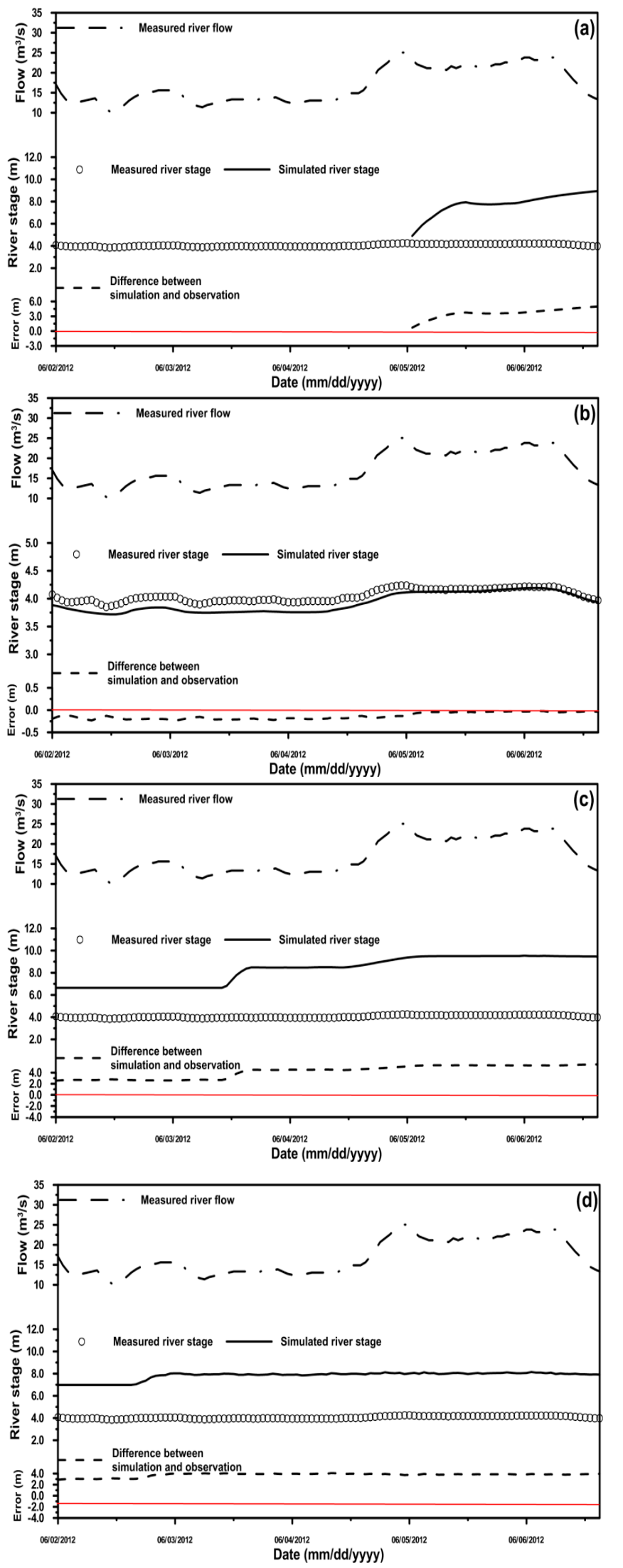

Figure 8. A comparison of the simulated and observed river stages at the Xinzhong station under low flow conditions using the 2D model with the: (a) original cross-section data; and resampled cross-section data according to: (b) the linear interpolation method; (c) the IDW method, and (d) the NN method. 

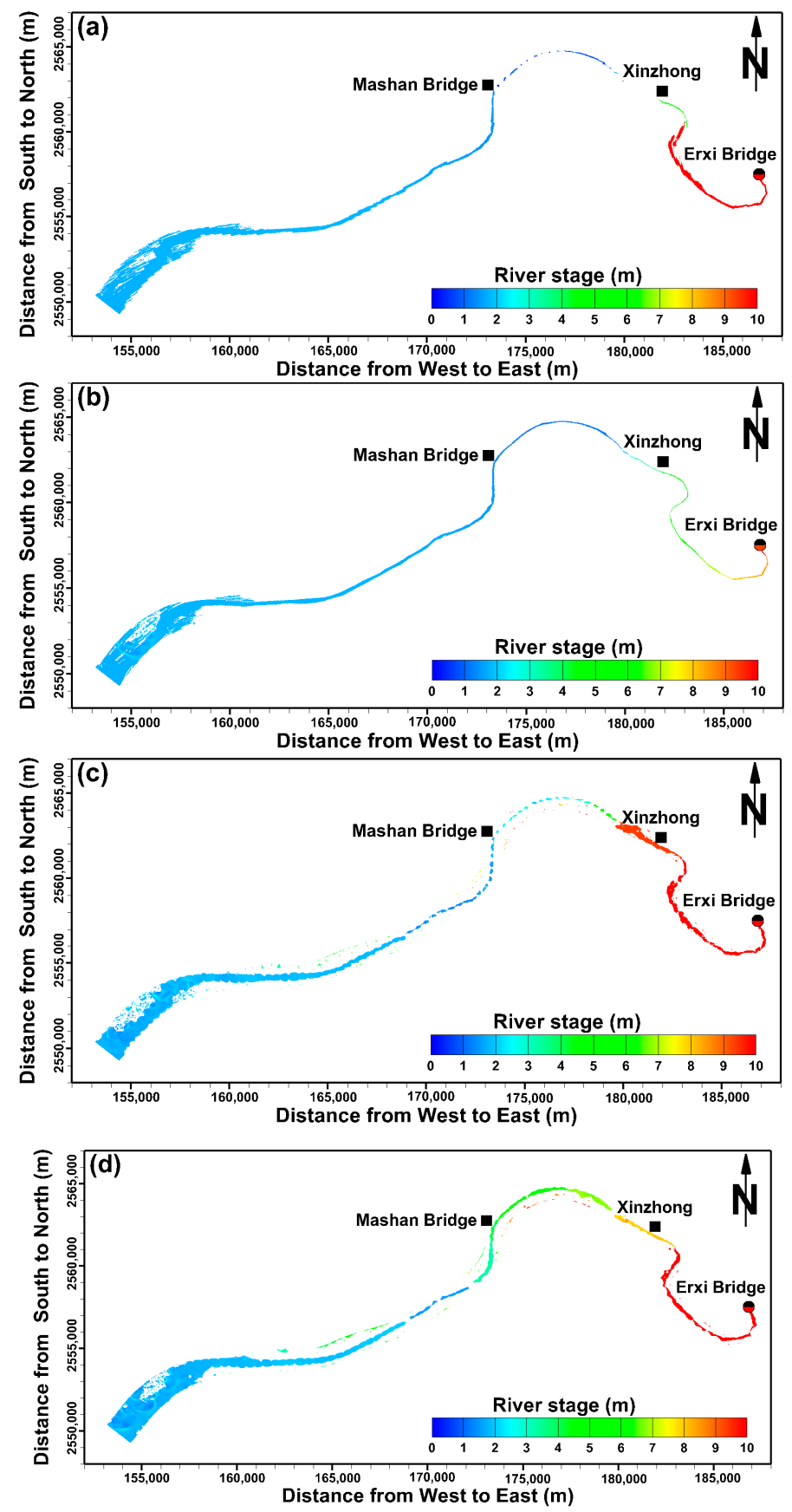

Figure 9. Simulated river stage distribution at 618 1:00 on 5 June 2012, under the low flow condition using the 2D model with the: (a) original cross-section data; and resampled cross-section data according to: (b) the linear interpolation method; (c) the IDW method; and (d) the NN method.

Figures 10 and 11 illustrate the model-data comparison of river stages, respectively, at the Mashan Bridge and the Xinzhong station under the high flow condition using the 2D model with the original and different resampled cross-section data. The simulated river stages using the resampled cross-section data (i.e., linear interpolation method) show good agreement with the measured river stages at both the Mashan Bridge and Xinzhong stations but overestimate when the river flows exceed approximately $1500 \mathrm{~m}^{3} / \mathrm{s}$. Although the simulated river stages using the original cross-section data show an acceptable result at the Mashan Bridge (Figure 10a), the simulated river stage cannot be lowered, even if there has been a decrease in the river flows (Figure 11a). This result means that the 
riverbed elevations interpolated by the original cross-section data are higher than the actual ones. The simulated river stages using the resampled cross-section data based on the IDW and NN methods extremely overestimate the measured river stages at both the Mashan Bridge and Xinzhong stations shown in Figure 10c,d and Figure 11c,d.
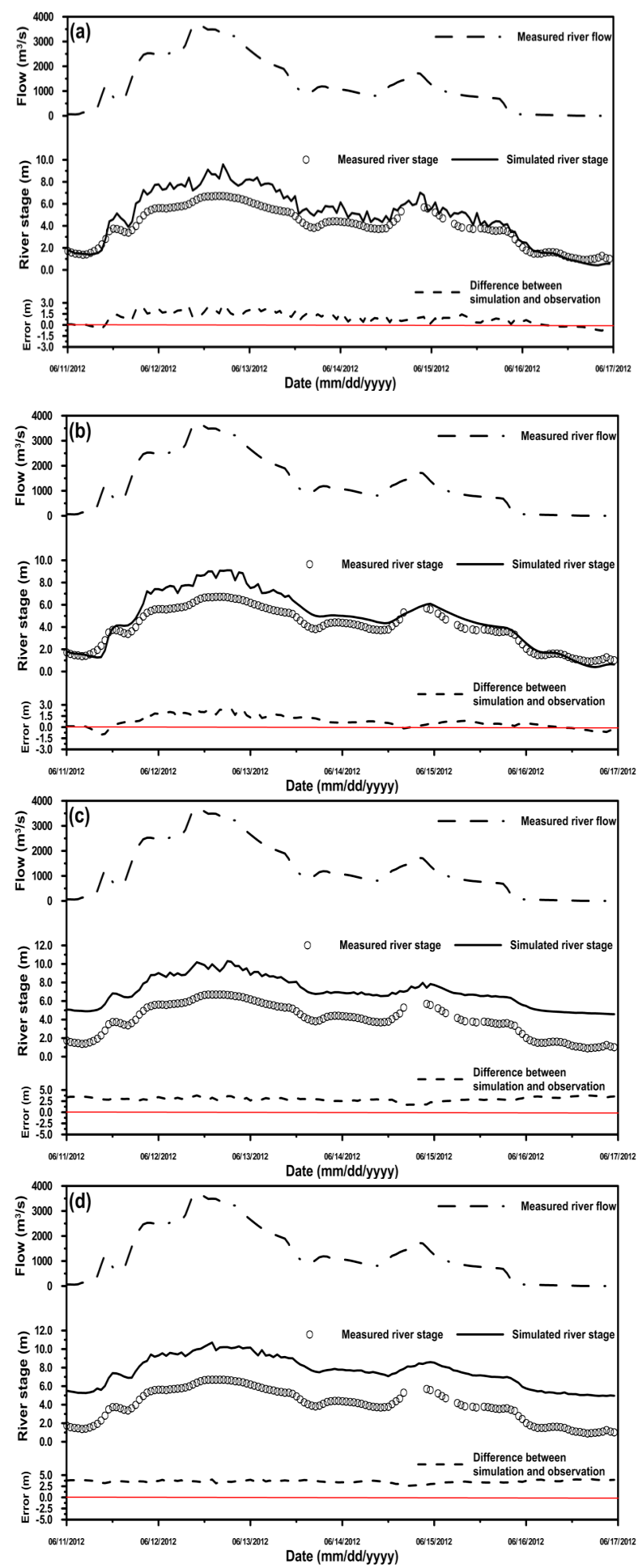

Figure 10. A comparison of the simulated and observed river stages at the Mashan Bridge under the high flow condition using the 2D model with the: (a) original cross-section data; and resampled cross-section data according to: (b) the linear interpolation method; (c) the IDW method; and (d) the NN method. 

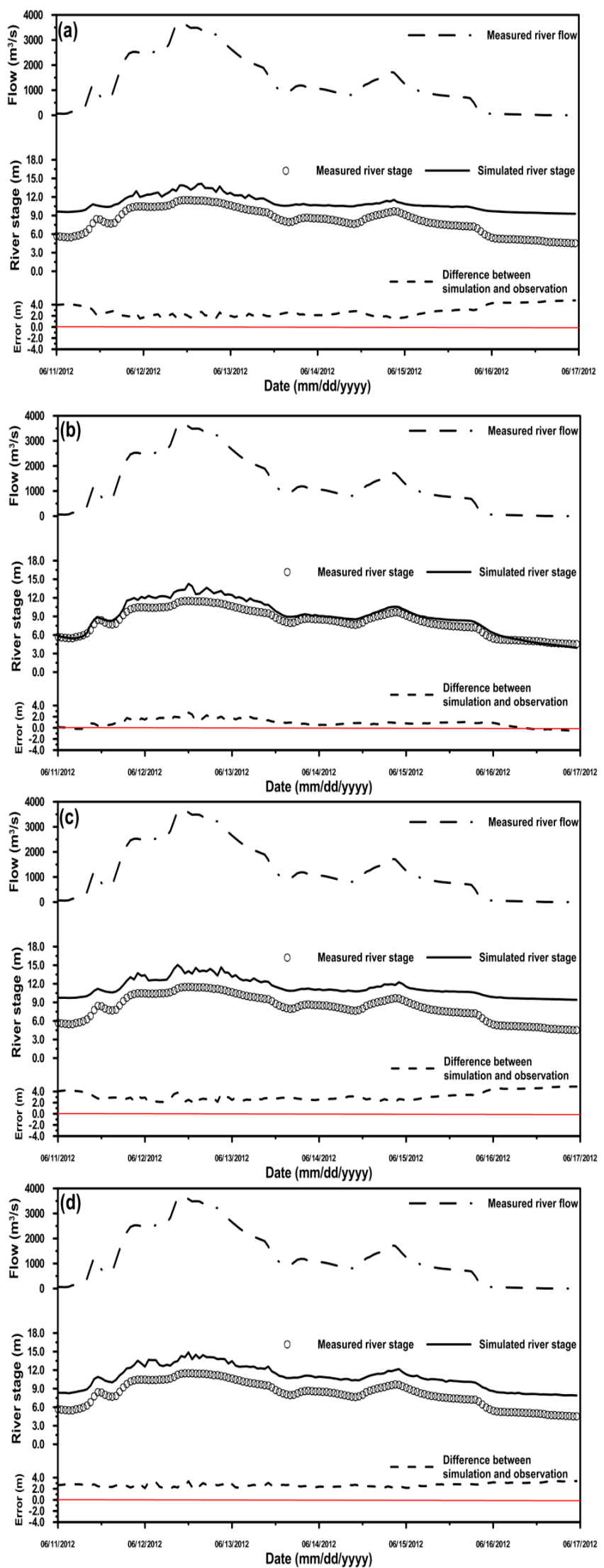

Figure 11. A comparison of the simulated and observed river stages at the Xinzhong station under high flow conditions using the 2D model with the: (a) original cross-section data; and resampled cross-section data according to: (b) the linear interpolation method; (c) the IDW method; and (d) the NN method. 
The river stage distribution at 12:00 on 12 June 2012, using the original and different resampled cross-section data is shown in Figure 12. Figure 12a,b displays similar simulated results, but the river stages around Xinzhong station are higher using the original cross-section data than those using resampled cross-section data based on the linear interpolation. Comparing to Figure $12 \mathrm{~b}-\mathrm{d}$, the simulated river stages between the Mashan Bridge and Xinzhong station using resample cross-section data according to the IDW and NN methods are extremely higher than those using the linear interpolation method. The trial-and-error approach was adopted to select the optimal parameter of bottom drag coefficient used in the model for simulating water stages. Based on the modeling results, the bottom drag coefficients are set to be 0.002 .
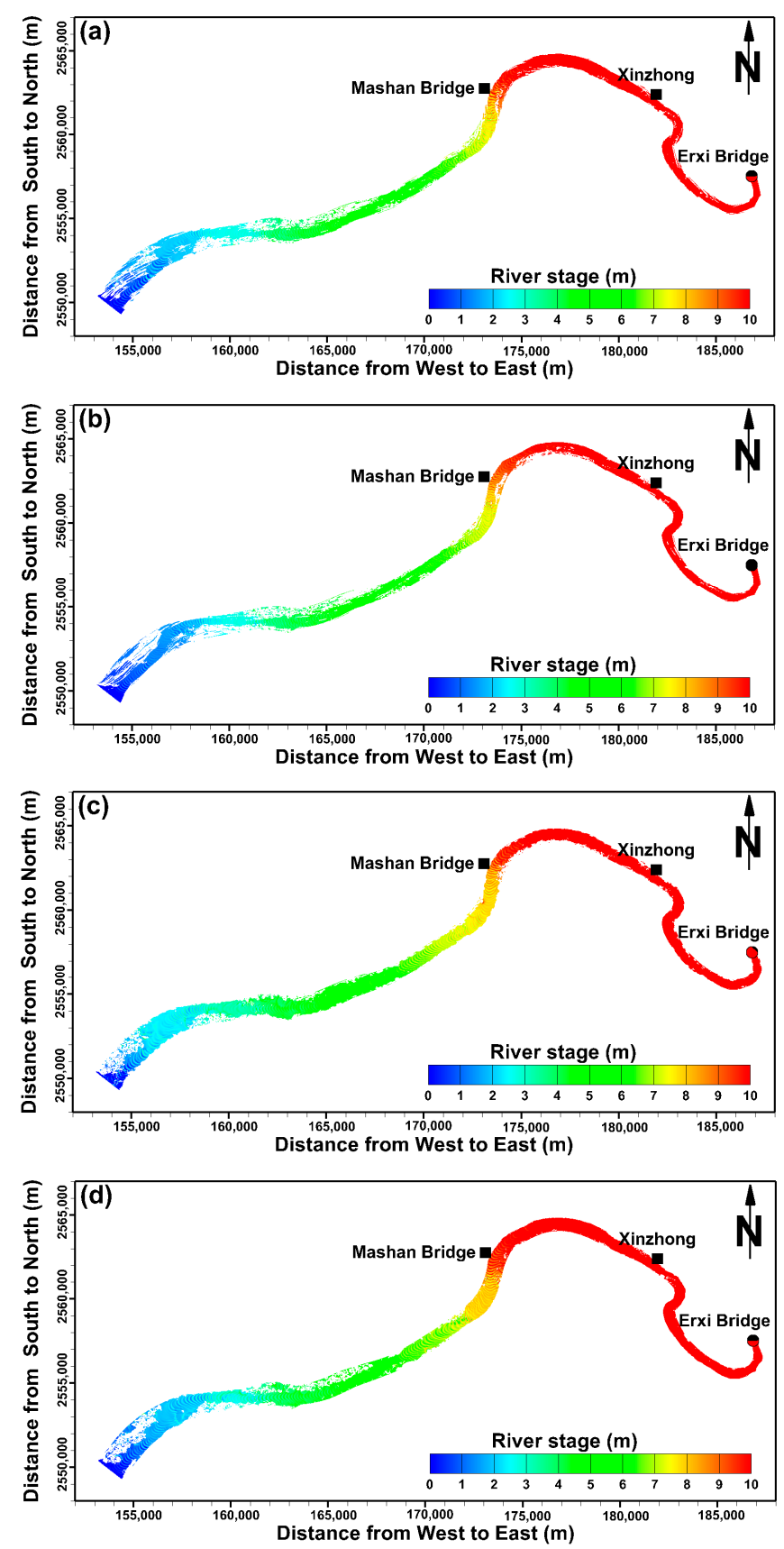

Figure 12. Simulated river stage distributions at 12:00 on 12 June 2012, under the high flow condition using the 2D model with the: (a) original cross-section data; and resampled cross-section data according to: (b) the linear interpolation method; (c) the IDW method; and (d) the NN method. 
Statistical errors between the simulated and measured river stages for different river bed cross-section data using the 2D model under low flow and high flow conditions are presented in Tables 1 and 2, respectively. The results indicate that the MAE, RMSE, and PBIAS values with the resampled cross-section data using the linear interpolation method are lower than those with the original and resample cross-section data using the IDW and NN methods at the Mashan Bridge and Xinzhong station under both the low and high flow conditions.

Table 1. Statistical error between the simulated and measured river stages under the low flow condition.

\begin{tabular}{lcccc}
\hline \multicolumn{1}{c}{ Condition } & Station & MAE $(\mathbf{m})$ & RMSE $(\mathbf{m})$ & PBIAS $(\%)$ \\
\hline 2D modeling with original & Mashan Bridge & 0.304 & 0.346 & -17.13 \\
cross-section data & Xinzhong & 3.627 & 3.750 & 87.090 \\
\hline 2D modeling with the linear & Mashan Bridge & 0.203 & 0.232 & 1.229 \\
interpolation method & Xinzhong & 0.133 & 0.151 & -3.285 \\
\hline \multirow{2}{*}{ 2D modeling with the IDW method } & Mashan Bridge & 1.190 & 1.250 & 214.385 \\
& Xinzhong & 4.220 & 4.367 & 104.055 \\
\hline \multirow{2}{*}{ 2D modeling with the NN method } & Mashan Bridge & 3.328 & 3.353 & 599.405 \\
& Xinzhong & 3.760 & 3.774 & 92.715 \\
\hline 3D modeling with the linear & Mashan Bridge & 0.216 & 0.253 & 3.390 \\
interpolation method & Xinzhong & 0.096 & 0.105 & -1.404 \\
\hline
\end{tabular}

Table 2. Statistical error between the simulated and measured river stages under the high flow condition.

\begin{tabular}{lcccc}
\hline \multicolumn{1}{c}{ Condition } & Station & MAE $(\mathbf{m})$ & RMSE (m) & PBIAS (\%) \\
\hline 2D modeling with original & Mashan Bridge & 1.018 & 1.238 & 22.981 \\
cross-section data & Xinzhong & 2.794 & 2.956 & 34.254 \\
\hline 2D modeling with the linear & Mashan Bridge & 0.911 & 1.135 & 19.670 \\
interpolation method & Xinzhong & 0.934 & 1.093 & 10.499 \\
\hline \multirow{2}{*}{ 2D modeling with the IDW method } & Mashan Bridge & 3.038 & 3.063 & 77.010 \\
& Xinzhong & 3.192 & 3.293 & 39.133 \\
\hline \multirow{2}{*}{ 2D modeling with the NN method } & Mashan Bridge & 3.613 & 3.623 & 91.595 \\
& Xinzhong & 2.690 & 2.711 & 32.978 \\
\hline 3D modeling with the linear & Mashan Bridge & 0.858 & 0.950 & 19.428 \\
interpolation method & Xinzhong & 0.546 & 0.645 & 6.267 \\
\hline
\end{tabular}

\subsection{Comparison of the Simulated River Stage Using the $2 D$ and $3 D$ Models}

To compare the performance between the 2D and 3D models on the simulation of the river stage, the samplings with the 2D and 3D models were conducted with the same grids, initial conditions, and boundary conditions using the resampled river bed cross-section data based on the linear interpolation method which is the best performance using 2D model shown in Tables 1 and 2. In the 2D and 3D models, the same bottom drag coefficients are used and set to be. The vertical eddy viscosity in 3D model is set to be $1.5 \times 10^{-4} \mathrm{~m}^{2} / \mathrm{s}$ [22].

The comparison of the simulated and measure river stages using the $2 \mathrm{D}$ and $3 \mathrm{D}$ models at the Mashan Bridge and the Xinzhong station under the low flow condition is presented in Figure 13. The simulated results of the 2D model and the 3D model are identical at the Mashan Bridge (Figure 13a), but the simulated river stage of the 3D model is slightly higher than that of the 2D model at the Xinzhong station (Figure 13b).

The comparison of the simulated and measured river stages of the 2D and 3D models under the high flow condition is shown in Figure 14. The 3D modeling results indicate that the simulated river stages are a closer match to the measured river stages compared to the 2D modeling results at both the Mashan Bridge (Figure 14a) and Xinzhong station (Figure 14b). Figure 15 presents the distributions of 
simulated river stage using the 3D model with the resampled cross-section data under the low flow (Figure 15a) and high flow (Figure 15b) conditions at 1:00 on 5 June 2012. The figure shows that the distributions of the simulated river stage are very reasonable.
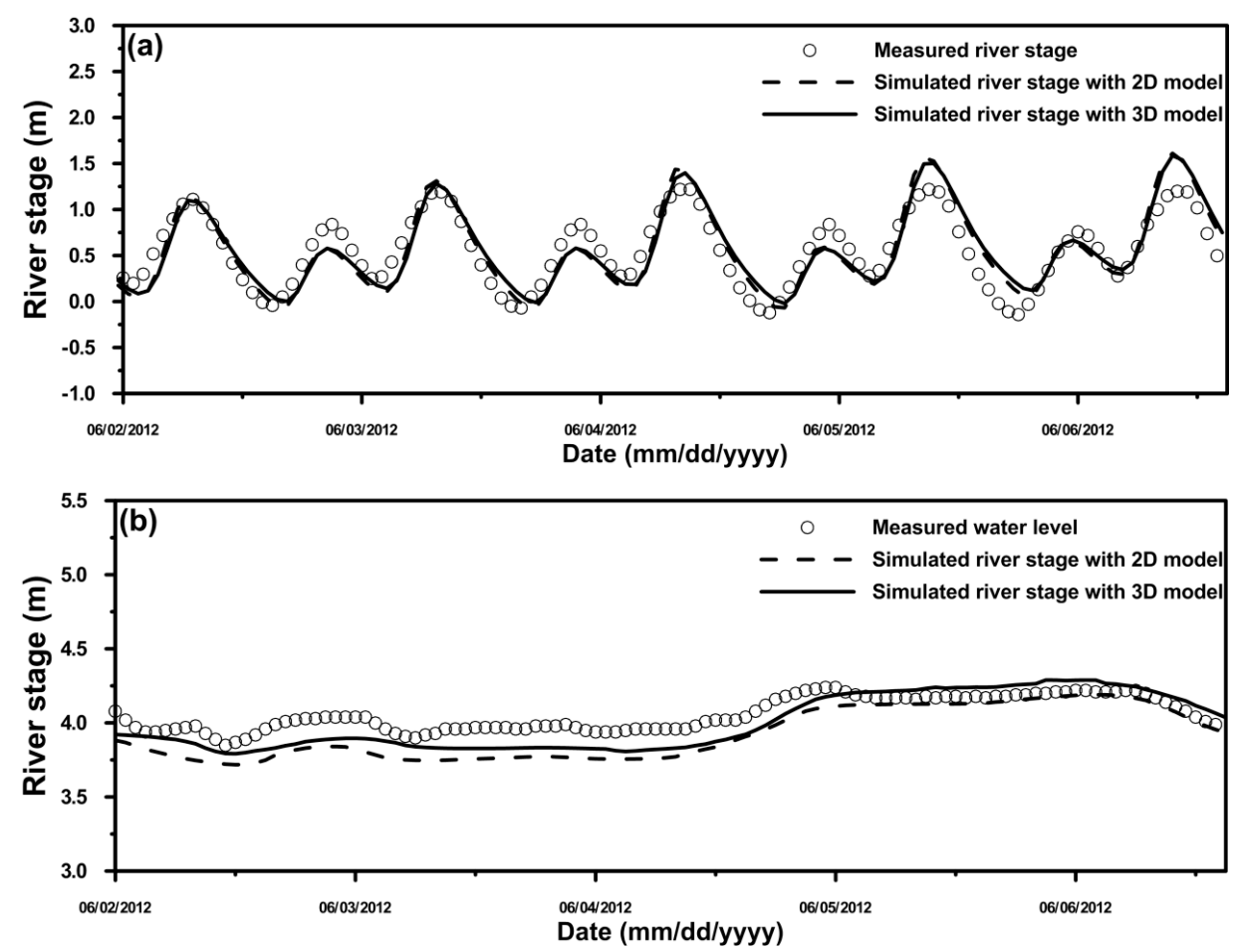

Figure 13. Comparison of the simulated river stages using the 2D and 3D models with the resampled cross-section data under the low flow condition at: (a) Mashan Bridge; and (b) Xinzhong station.
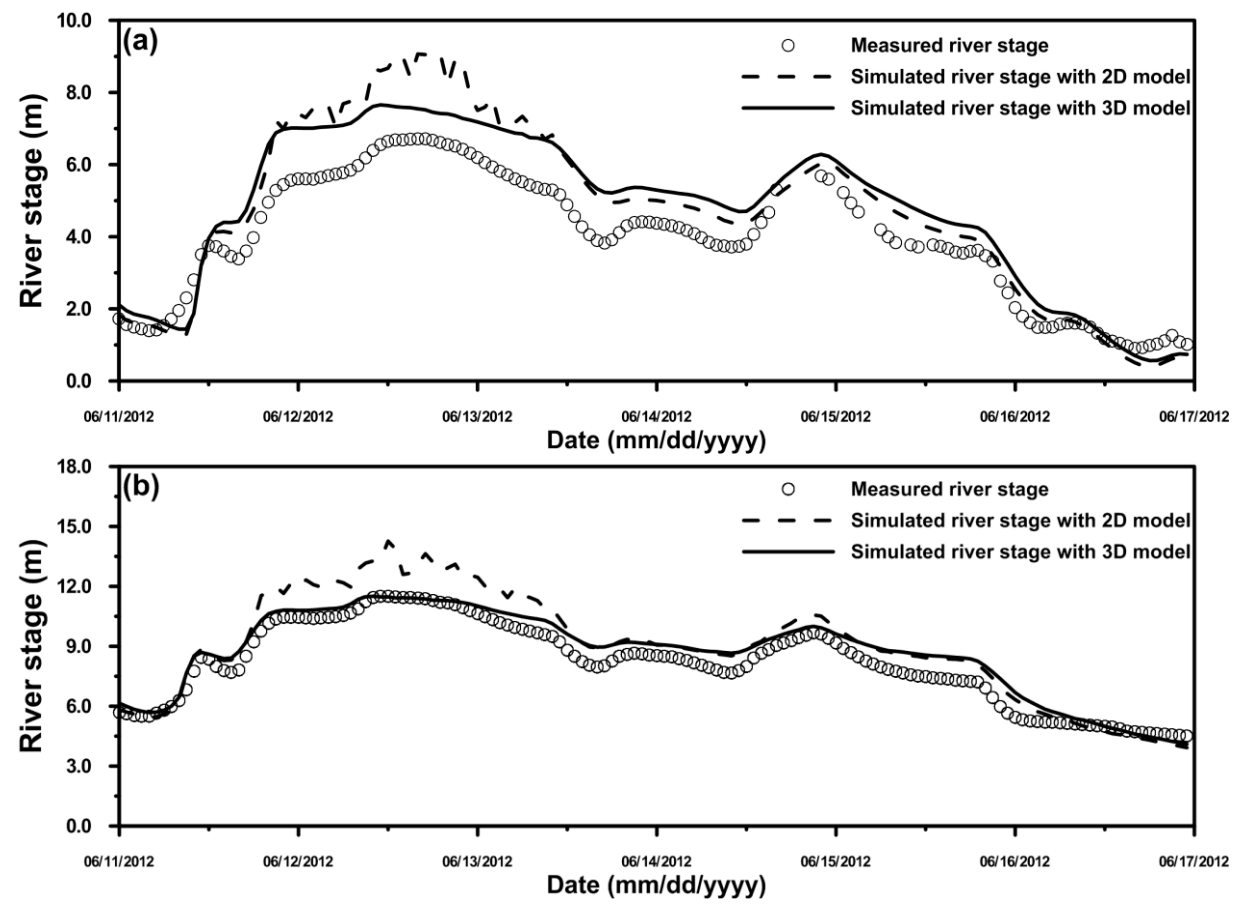

Figure 14. Comparison of the simulated river stages using the 2D and 3D models with the resampled cross-section data under the high flow condition at: (a) Mashan Bridge; and (b) Xinzhong station. 

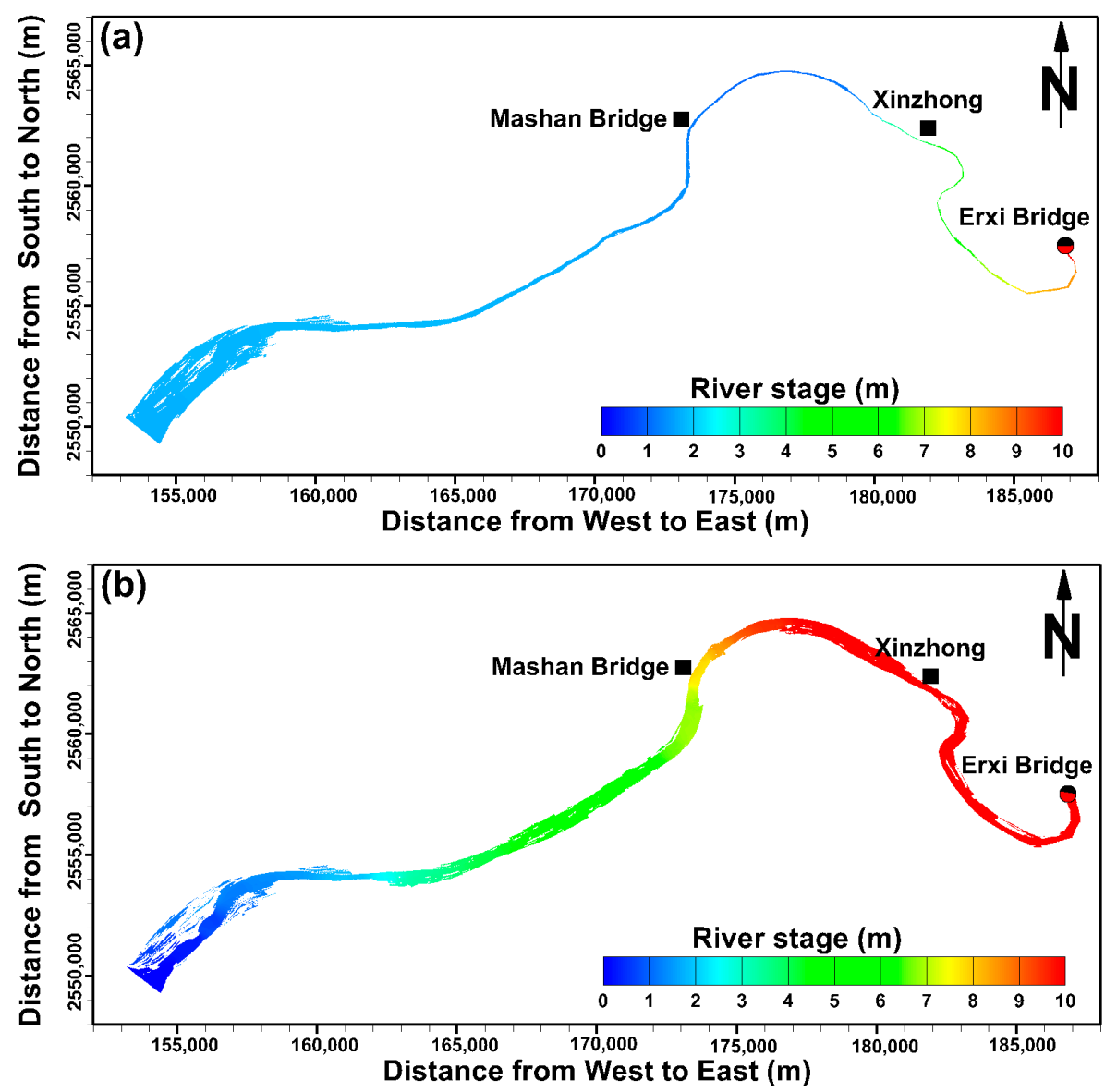

Figure 15. Simulated river stage distribution using the 3D model with the resampled cross-section data: (a) at 1:00 on 5 June 2012 (low flow condition); and (b) at 12:00 on 12 June 2012 (high flow condition).

To compare the performance of the 2D and 3D models using the resampled cross-section data based on the linear interpolation method, the statistical errors for the low flow and high flow conditions are presented in Tables 1 and 2, respectively. We can observe that the performance of the 2D model is better than that of the 3D model with the low condition at the Xinzhong station, whereas the performance of the 2D model is inferior to that of the 3D model at the Mashan Bridge (Table 1). For the high flow condition, the performance of the 3D model is better than that of the 2D model at both the Mashan Bridge and Xinzhong station (Table 2).

\subsection{Model Sensitivity}

Prandle [32] reported that for tidal propagation in depths greater than $50 \mathrm{~m}$, bottom friction is of secondary importance and 2D models are adequate to calculate integrated transport. Conversely, the increasing importance of both bottom friction and vertical eddy viscosity in shallow water indicated the requirement for 3D models. Sensitivity analysis is a powerful methodology that can be used to improve the understanding of how the bottom drag coefficient and the vertical eddy viscosity affects the river stages in the Tsengwen River. The sensitivity analysis was conducted by running the 2D and 3D models with all the conditions described in previous section, except for the bottom drag coefficient and the vertical eddy viscosity. The original base depended on the simulation of low flow and high flow conditions.

To investigate the effects of bottom drag coefficient on the river stage, the 2D and 3D models using the resampled cross-section data based on the linear interpolation method were run using two alternative cases. One method calculated the value of bottom drag coefficient $50 \%$ higher than the 
original base run, and the other method calculated the value of bottom drag coefficient $50 \%$ lower than the original case run. Tables 3 and 4 show the modeling results of sensitivity runs under low flow and high flow conditions, respectively. The maximum rate of changing river stage was used to evaluate the results of model sensitivity. The maximum rate $(M R)$ is given by the following formula:

$$
M R=\frac{\eta_{\text {sens }}-\eta_{\text {base }}}{\eta_{\text {base }}} \times 100 \%
$$

where $\eta_{\text {base }}$ is the river stage for the base run and $\eta_{\text {sens }}$ is the river stage for the sensitivity run. Positive and negative values of maximum rate represent the increase and decrease in river stage, respectively.

Table 3. The influence of model sensitivity runs on river stage under low flow condition.

\begin{tabular}{lcc}
\hline \multicolumn{1}{c}{ Condition } & Station & Maximum Rate of River Stage (\%) \\
\hline \multirow{2}{*}{ 2D modeling with increasing 50\% BDC } & Mashan Bridge & 0.615 \\
& Xinzhong & 0.081 \\
\hline \multirow{2}{*}{ 2D modeling with decreasing 50\% BDC } & Mashan Bridge & -1.037 \\
& Xinzhong & -0.069 \\
\hline \multirow{2}{*}{ 3D modeling with increasing 50\% BDC } & Mashan Bridge & 0.208 \\
& Xinzhong & 0.002 \\
\hline \multirow{2}{*}{ 3D modeling with decreasing 50\% BDC } & Mashan Bridge & -0.353 \\
& Xinzhong & -0.005 \\
\hline \multirow{2}{*}{ 3D modeling with increasing 50\% VEV } & Mashan Bridge & 0.001 \\
& Xinzhong & 0.009 \\
\hline \multirow{2}{*}{ 3D modeling with decreasing 50\% VEV } & Mashan Bridge & -0.006 \\
& Xinzhong & -0.007 \\
\hline
\end{tabular}

Notes: BDC: Bottom drag coefficient; VEV: Vertical eddy viscosity

Table 4. The influence of model sensitivity runs on river stage under high flow condition.

\begin{tabular}{ccc}
\hline \multicolumn{1}{c}{ Condition } & Station & Maximum Rate of River Stage (\%) \\
\hline \multirow{2}{*}{ 2D modeling with increasing 50\% BDC } & Mashan Bridge & 2.612 \\
& Xinzhong & 5.960 \\
\hline \multirow{2}{*}{ 2D modeling with decreasing 50\% BDC } & Mashan Bridge & -0.267 \\
& Xinzhong & -4.217 \\
\hline \multirow{2}{*}{ 3D modeling with increasing 50\% BDC } & Mashan Bridge & 1.309 \\
& Xinzhong & 0.329 \\
\hline \multirow{2}{*}{ 3D modeling with decreasing 50\% BDC } & Mashan Bridge & -0.0003 \\
& Xinzhong & -0.0001 \\
\hline \multirow{2}{*}{ 3D modeling with increasing 50\% VEV } & Mashan Bridge & 0.943 \\
& Xinzhong & 0.506 \\
\hline \multirow{2}{*}{ 3D modeling with decreasing 50\% VEV } & Mashan Bridge & -0.945 \\
& Xinzhong & -0.508 \\
\hline
\end{tabular}

Notes: BDC: Bottom drag coefficient; VEV: Vertical eddy viscosity

The maximum rates of changing water stage as a result of increasing bottom drag coefficient are $0.615 \%$ and $0.08 \%$, respectively, at the Mashan Bridge and Xinzhong station using 2D model under low flow condition, whereas the maximum rates of changing water stage as a result of decreasing bottom drag coefficient were $-1.037 \%$ and $-0.069 \%$, respectively (Table 3 ). The maximum rates of changing water stage as a result of increasing bottom drag coefficient are $2.612 \%$ and $5.96 \%$, respectively, at the Mashan Bridge and Xinzhong station using 2D model under high flow condition, whereas the maximum rates of changing water stage as a result of decreasing bottom drag coefficient are $-0.267 \%$ 
and $-4.217 \%$, respectively (Table 4). The results of model sensitivity using 3D under low and high flow conditions are also displayed in Tables 3 and 4. We found that the increasing bottom drag coefficient resulted in the raising river stage. It is the reason that the increasing the bottom drag coefficient can increase the total resistance and lead to decrease the velocity which results in the raise of river stage [33]. The modeling results indicate that the change of bottom drag coefficient has a minor impact on river stage using $2 \mathrm{D}$ and $3 \mathrm{D}$ models.

The vertical eddy viscosity was included in 3D model only instead of in 2D model, because the vertical term has been averaged in horizontal 2D model. Therefore the model sensitivity runs to comprehend the influence of vertical eddy viscosity on water stage were conducted using 3D hydrodynamic model. The maximum rates for increasing vertical eddy viscosity are $0.943 \%$ and $0.506 \%$, respectively, at the Mashan Bridge and Xinzhong station under high flow condition, whereas the maximum rates for decreasing vertical eddy viscosity are $-0.945 \%$ and $-0.508 \%$, respectively (Table 4). The maximum rates for increasing and decreasing vertical eddy viscosities under low flow condition (Table 3) are lower than those under high flow condition (Table 4).

\section{Discussion}

A large amount of accurate measurements of the river cross-section data is indispensable for simulating river stages using 2D and 3D models. However, the measured river cross-section data are usually sparse in spatial resolution. If the original (sparse) river cross-section data are employed, a rough and uneven river bed is created. This phenomenon is especially obvious in a meandering river segment (shown in Figures 5a and 6a) because the distance between two measured river cross sections is too far to make a correct interpolation. Besides, an appropriate interpolation method is crucial to construct accurate river bed for simulating river stages.

Because of the rugged river bed elevations produced by sparse river cross-section data or inappropriate interpolation method, the water may be blocked in the channel and consequently delays the arrival time of water from upstream to downstream, resulting in the an extremely high river stage at upstream reaches (shown in Figure 8a). A similar phenomenon has been reported by Cook and Merwade [14]. They demonstrated that different amounts of the river cross-section data produced different amounts of coverage of the water surface. The simple method presented in this study was used to overcome the problem of sparse river cross-section data and to produce accurate river bed for simulating water stages in the Tsengwen River.

From the physical point of view, some inherent differences exist between 2D and 3D models. In 2D model, bottom shear stress directly translates into mitigating the depth-averaged velocity, and consequently increases river stage [33]. The horizontal velocity is depth-averaged (i.e., uniform in the vertical direction) and vertical shear is absent [27]. However, the bottom shear stress balances the vertical shear in 3D model and only directly affects the horizontal velocity near the bottom cell. Besides, the numerical method to solve the free-surface elevation in the SELFE-3D is imposed a restriction to make a positive-define matrix, thus enhances stability for large friction in shallow areas [26]. This method avoids wave-like free-surface elevations occurring in the SELFE-3D model under high flow condition. Although simulated river stage using 3D model is slight inferior than 2D model at the Mashan Bridge under low flow condition (see Table 1). We cannot conclude that 2D model has better performance than 3D model on simulation of river stage under low flow condition because this issue may not occur in other tidal rivers.

In Figure 14, the simulated river stage using the 2D model is higher than that using the 2D model under the high flow condition when the river flow exceeds $1500 \mathrm{~m}^{3} / \mathrm{s}$. It can be explained using the simplified momentum equation. If the Coriolis force, tidal effect, atmospheric pressure at the free surface, and wind shear stress are neglected, and a steady state is assumed, the momentum equation can be expressed as:

$$
\frac{\partial \eta}{\partial x}=-\frac{\tau_{b x}}{\rho_{0} g H}
$$


where $H=\eta+h ; h$ is the bathymetric depth; $\eta$ is the free-surface elevation; $g$ is the acceleration due to gravity; $\rho_{0}$ is the density of water; and $\tau_{b x}$ is the bottom shear stress in $x$ direction.

Equation (8) shows that $\eta$ is affected by the bottom shear stress in the models. The equation indicates that $\eta$ increases with increasing bottom shear stress. The velocity gradient $\left(\frac{\partial u}{\partial z}\right)$ is positive based on the bottom shear stress $(\tau)$. One layer is used to calculate $\frac{\partial u}{\partial z}$ in the 2D model, while the top of the bottom cell is applied in the 3D model. Because the depth-averaged velocities in the 2D model are higher than the bottom velocities in the 3D model under the high flow condition, the bottom shear stress and free-surface elevation $(\eta)$ are also higher using the 2D model than those using the 3D model, resulting in a worse performance when the 2D model is used (Figure 14). A similar theory used to discuss the wind stress tide can be found in Dean and Dalrymple [34].

The simulated river stages with 2D model were more sensitive to the changes of bottom drag coefficient than those with 3D model in the Tsengwen River (see Table 3) because the bottom shear stresses in 2D model directly affect depth-averaged velocities and consequently river stages. The vertical shear stress induced by vertical eddy viscosity near the bottom in the 3D model is relatively small to bottom shear stress. Therefore the change of vertical eddy viscosity has insignificant change of simulated river stages using 3D model (Table 3).

Miller and Cluer [35] examined the water level response to different eddy viscosity. They also found that the increasing eddy viscosity slightly raised the water level. However, in the current study, the modeling results reveal that the change of vertical eddy viscosity is insensitive to river stage.

\section{Conclusions}

This study applied three algorithms including linear interpolation, IDW, and NN to refine river cross-section data based on original data. The resampled cross-section data based on the linear interpolation satisfactorily maintains the topographic and morphological features of the river channel, especially at the meandering river reach. The river channel constructed by the resampled cross-section data based on the linear interpolation is more flat and smooth than the model created by the original cross-section data, IDW, and NN interpolation. The 2D high-resolution unstructured-grid hydrodynamic model was adopted to assess the performance between the simulated and measured river stages with the original and resampled cross-section data under low flow and high flow conditions. The results indicate that the simulated river stages are improved significantly to match the measured river stages using the resampled cross-section data based on the linear interpolation at the tidal river and non-tidal river stations.

Furthermore, the performance between the simulated and measured river stages using the 2D and $3 \mathrm{D}$ models incorporated with the resampled cross-section data based on the linear interpolation were evaluated. The results show that the simulated river stages using the 2D and 3D models reproduce the measured river stages at both the tidal and non-tidal river stations under the low flow condition. However, the simulated river stages using the 2D model overestimate the measured river stages at both the tidal and non-tidal river stations under the high flow condition. The 2D model is appropriate for real-time river stage prediction for flash flood warning because it requires less computational time, but the 3D model provides a more accurate simulation of the river stage. The model sensitivity was conducted by increasing and decreasing the bottom drag coefficient and vertical eddy viscosity. The modeling results indicate the change of bottom drag coefficient has a minor impact on river stage and the change of vertical eddy viscosity is insensitive to river stage.

The algorithm developed for riverbed interpolation is very useful in cases where the river bathymetry is frequently modified by hydrological events, for example, in restored river sections. This is because periodic flow modeling is required to assess how river morphology affects ecological aspects. Further study will be needed to define more specifically the optimal cross-section spacing in relation to the grid resolution. 
Acknowledgments: This project was funded by the Ministry of Science and Technology (MOST), Taiwan, grant Nos. 104-2625-M-239-002 and 105-2625-M-865-002. The authors would like to thank the Taiwan Water Resources Agency for providing the measured data.

Author Contributions: Wen-Cheng Liu supervised the progress of the MOST project and served as a general editor. Wei-Bo Chen performed the data collection, model establishment simulations, and discussed the results with Wen-Cheng Liu. All authors read and approved the final manuscript.

Conflicts of Interest: The authors declare no conflict of interest.

\section{Appendix A}

A semi-implicit finite element Eulerian-Lagrangian algorithm is used in SELFE-3D to solve the three-dimensional shallow-water equations with the hydrostatic and Boussinesq approximations. The equations in the Cartesian frame of reference are given below:

$$
\begin{gathered}
\frac{\partial u}{\partial z}+\frac{\partial v}{\partial z}+\frac{\partial w}{\partial z}=0 \\
\frac{\partial \eta}{\partial t}+\frac{\partial}{\partial x} \int_{-h}^{\eta} u d z+\frac{\partial}{\partial y} \int_{-h}^{\eta} v d z=0 \\
\frac{D u}{D t}=f v-\frac{\partial}{\partial x}\left\{g(\eta-\alpha \hat{\psi})+\frac{P_{A}}{\rho_{0}}\right\}-\frac{g}{\rho_{0}} \int_{z}^{\eta} \frac{\partial \rho}{\partial x} d z+\frac{\partial}{\partial x}\left(\mu \frac{\partial u}{\partial x}\right)+\frac{\partial}{\partial y}\left(\mu \frac{\partial u}{\partial y}\right)+\frac{\partial}{\partial z}\left(v \frac{\partial u}{\partial z}\right) \\
\frac{D v}{D t}=-f u-\frac{\partial}{\partial y}\left\{g(\eta-\alpha \hat{\psi})+\frac{P_{A}}{\rho_{0}}\right\}-\frac{g}{\rho_{0}} \int_{z}^{\eta} \frac{\partial \rho}{\partial y} d z+\frac{\partial}{\partial x}\left(\mu \frac{\partial v}{\partial x}\right)+\frac{\partial}{\partial y}\left(\mu \frac{\partial v}{\partial y}\right)+\frac{\partial}{\partial z}\left(v \frac{\partial v}{\partial z}\right)
\end{gathered}
$$

where $\eta(x, y, t)$ is the free-surface elevation; $h(x, y)$ is the bathymetric depth; $u(x, y, z, t)$ and $v(x, y, z, t)$ are the horizontal velocity in $x, y$ direction, respectively; $w(x, y, z, t)$ is the vertical velocity; $f$ is the Coriolis factor; $g$ is the acceleration due to gravity; $\hat{\psi}$ is the earth's tidal potential; $\alpha$ is the effective earth elasticity factor; $\rho$ is the density of water; $\rho_{0}$ is reference density of water; $P_{A}(x, y, t)$ is the atmospheric pressure at the free surface; $v$ is the vertical eddy viscosity; and $\mu$ is the horizontal eddy viscosity.

The vertical boundary conditions for the momentum equation, especially the bottom boundary condition, play an important role in the formulation of the numerical SELFE-3D model. The balance between the internal Reynolds stress and the applied shear stress at the water surface is enforced in SELFE-3D:

$$
v \frac{\partial u}{\partial z}=\tau_{s}, \text { at } z=\eta
$$

where $\tau_{s}$ is the wind stress, which can be expressed as

$$
\begin{aligned}
& \tau_{s x}=\rho_{a} C_{s} \sqrt{\left(U_{a}-u\right)^{2}+\left(V_{a}-v\right)^{2}}\left(U_{a}-u\right) \\
& \tau_{s y}=\rho_{a} C_{s} \sqrt{\left(U_{a}-u\right)^{2}+\left(V_{a}-v\right)^{2}}\left(V_{a}-v\right)
\end{aligned}
$$

where $U_{a}$ and $V_{a}$ are the $x$ and $y$ components, respectively, at a 10-m height wind speed, $W$, which is generated from the prototypical typhoon model; $\rho_{a}$ is the air density; and $C_{s}$ is the wind drag coefficient that depends on the wind speed. The wind drag coefficient, $C_{s}$, is given by Large and Pond [36] and Powell et al. [37].

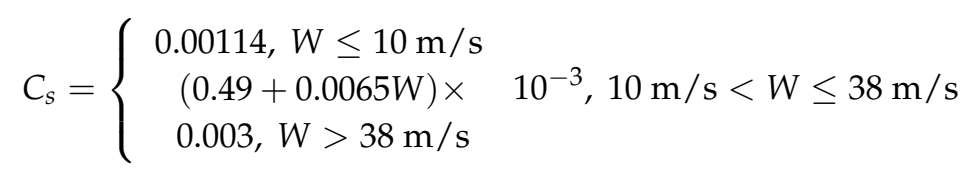

The bottom boundary layer is typically not well described in ocean models; thus, the no-slip condition at the sea or river bottom is replaced by a balance between the internal Reynolds stress and the bottom frictional stress: 


$$
v \frac{\partial \mathrm{u}}{\partial z}=\tau_{b}, \text { at } z=-h
$$

where $\tau_{b}$ is the bottom stress. The bottom friction stress is given by a quadratic drag law:

$$
\begin{aligned}
\tau_{b x} & =\rho C_{b} \sqrt{u^{2}+v^{2}} u \\
\tau_{b y} & =\rho C_{b} \sqrt{u^{2}+v^{2}} v
\end{aligned}
$$

where $C_{b}$ is the drag coefficient.

\section{Appendix B}

The governing equations of SELFE-2D are given as below:

$$
\begin{gathered}
\frac{\partial \eta}{\partial t}+\frac{\partial u H}{\partial x}+\frac{\partial v H}{\partial y}=0 \\
\frac{D u}{D t}=f v-\frac{\partial}{\partial x}\{g(\eta-\alpha \hat{\psi})\}-\frac{\tau_{b x}}{\rho_{0} H} \\
\frac{D v}{D t}=-f u-\frac{\partial}{\partial y}\{g(\eta-\alpha \hat{\psi})\}-\frac{\tau_{b y}}{\rho_{0} H}
\end{gathered}
$$

where $H=\eta+h$

\section{References}

1. Yoshida, H.; Dittrich, A. 1D unsteady-state flow simulation of a section of the upper Rhine. J. Hydrol. 2002, 269, 78-88. [CrossRef]

2. Juez, C.; Lacasta, A.; Murillo, J.; Garcia-Navarro, P. An efficient GPU implementation for a faster simulation of unsteady bed-load transport. J. Hydraul. Res. 2016, 54, 275-288. [CrossRef]

3. Caviedes-Voullieme, D.; Morales-Hernandez, M.; Lopez-Marijuan, I.; García-Navarro, P. Reconstruction of 2D river beds by appropriate interpolation of $1 \mathrm{D}$ cross-sectional information for flood simulation. Environ. Model. Softw. 2014, 61, 206-228. [CrossRef]

4. Merwade, V.M.; Cook, A.; Coonrod, J. GIS techniques for creating river terrain models for hydrodynamic modeling and flood inundation mapping. Environ. Model. Softw. 2008, 23, 1300-1311. [CrossRef]

5. Chen, W.B.; Liu, W.C.; Wu, C.Y. Coupling of a one-dimensional river routing model and a three-dimensional ocean model to predict overbank flows in a complex river-ocean system. Appl. Math. Model. 2013, 37, 6163-6176. [CrossRef]

6. Kasvi, E.; Alho, P.; Lotsari, E.; Wang, Y.S.; Kukko, A.; Hyyppa, H.; Hyppa, J. Two-dimensional and three-dimensional computational models in hydrodynamic and morphodynamic reconstructions of a river bend: Sensitivity and functionality. Hydrol. Process. 2015, 29, 1604-1629. [CrossRef]

7. Horritt, M.S.; Bates, P.D.; Mattinson, M.J. Effects of mesh resolution and topographic representation in 2D finite volume models of shallow water fluvial flow. J. Hydrol. 2006, 329, 306-314. [CrossRef]

8. Casas, A.; Benito, G.; Thorndycraft, V.; Rico, M. The topographic data source of digital terrain models. Earth Surf. Process. Landf. 2006, 31, 444-456. [CrossRef]

9. Flanagin, M.; Grenotton, A.; Ratcliff, J.; Shaw, K.B.; Sample, J.; Abdelguerfi, M. Hydraulic splines-a hybrid approach to modeling river channel geometries. Comput. Sci. Eng. 2007, 9, 4-15. [CrossRef]

10. Jha, S.K.; Mariethoz, G.; Kelly, B.F. Bathymetry fusion using multiple-point geostatistics: Novelty and challenges in representing non-stationary bedforms. Environ. Model. Softw. 2013, 50, 66-76. [CrossRef]

11. Tomczak, M. Spatial interpolation and it uncertainty using automated anisotropic inverse distance weighting (IDW)-cross-validation/Jackknife approach. J. Geogr. Inform. Decis. Anal. 1998, 2, 18-30.

12. Schappi, B.; Perona, P.; Schneider, P.; Burlando, P. Integrating river cross section measurements with digital terrain models for improved flow modeling applications. Comput. Geosci. 2010, 36, 707-716. [CrossRef]

13. Legleiter, C.J.; Kyriakidis, P.C. Spatial prediction of river channel topography by kriging. Earth Surf. Process. Landf. 2008, 33, 841-867. [CrossRef] 
14. Cook, A.; Merwade, V. Effect of topographic data, geometric configuration and modeling approach on flood inundation mapping. J. Hydrol. 2009, 377, 131-142. [CrossRef]

15. Horritt, M.S.; Bates, P.D. Effects of spatial resolution on a raster based model of flood flow. J. Hydrol. 2001, 253, 239-249. [CrossRef]

16. Liu, X. Airborne LiDAR for DEM generation: Some critical issues. Prog. Phys. Geogr. 2008, 32, 31-49.

17. Wang, C.K.; Philpot, W.D. Using airborne bathymetric Lidar to detect bottom type variation in shallow waters. Remote Sens. Environ. 2007, 106, 123-135. [CrossRef]

18. Dal Cin, C.; Moens, L.; Dierickx, P.; Bastin, G.; Zech, Y. An integrated approach for realtime floodmap forecasting on the Belgian Meuse River. Nat. Hazards 2005, 36, 237-256.

19. Merwade, V. Effect of spatial trends on interpolation of river bathymetry. J. Hydrol. 2009, 371, 169-181. [CrossRef]

20. Zhang, Y.; Xian, C.; Chen, H.; Grieneisen, M.L.; Liu, J.; Zhang, M. Spatial interpolation of river channel topography using the shortest temporal distance. J. Hydrol. 2016, 542, 450-462. [CrossRef]

21. Dyer, K.R. Estuaries: A Physical Introduction; Wiley: New York, NY, USA, 1997.

22. Chen, W.B.; Liu, W.C. Modeling flood inundation induced by river flow and storm surge over a river basin. Water 2014, 6, 3182-3199. [CrossRef]

23. Wei, H.P.; Yeh, K.C.; Liou, J.J.; Chen, Y.M.; Cheng, C.T. Estimating the risk of river flow under climate change in the Tsengwen River Basin. Water 2016, 8, 81. [CrossRef]

24. Isaaks, E.H.; Srivastava, R.M. Applied Geostatistics; Oxford University Press: New York, NY, USA, 1989; pp. 257-258.

25. Sibson, R. A brief description of natural neighbor interpolation. In Interpreting Multivariate Data; Barnett, V., Ed.; John Wiley and Sons: New York, NY, USA, 1981; Volume 21, pp. 21-36.

26. Zhang, Y.; Baptisa, A.M. SELFE: A semi-implicit Eulerian-Lagrangian finite-element model for cross-scale ocean circulation. Ocean Model. 2008, 21, 71-96. [CrossRef]

27. Zhang, Y.J.; Witter, R.C.; Priest, G.R. Tsunami-tide interaction in 1964 Prince William Sound tsunami. Ocean Model. 2011, 40, 246-259. [CrossRef]

28. Zhang, Y.; Ye, F.; Stanev, E.V.; Grashorn, S. Seamless cross-scale modeling with SCHISM. Ocean Model. 2016, 102, 64-81. [CrossRef]

29. Juez, C.; Murillo, J.; Garcia-Navarro, P. 2D simulation of granular flow over irregular steep slopes using global and local coordinates. J. Comput. Phys. 2013, 255, 166-204. [CrossRef]

30. Langendoen, E.J.; Mendoza, A.; Abad, J.D.; Tassi, P.; Wang, D.; Ata, R.; Kadi Abederrezzak, E.K.; Hevouet, J.M. Improved numerical modeling of morphodynamics of rivers with steep banks. Adv. Water Resour. 2016, 93, 4-14. [CrossRef]

31. Zu, T.; Gana, J.; Erofeevac, S.Y. Numerical study of the tide 456 and tidal dynamics in the South China Sea. Deep Sea Res. Part I 2008, 55, 137-154. [CrossRef]

32. Prandle, D. The influence of bed friction and vertical eddy viscosity on tidal propagation. Cont. Shelf Res. 1997, 17, 1367-1374. [CrossRef]

33. Kim, T.B.; Choi, S. Depth-averaged modeling of vegetated open-channel flows using finite element method. In Advances in Water Resources and Hydraulic Engineering, Proceedings of the 16th IAHR-APD Congress and 3rd Symposium of IAHR-ISHS; Spring: Berlin/Heidelberg, Germany, 2008; Volume 2, pp. 411-416.

34. Dean, R.G.; Dalrymple, R.A. Coastal Processes with Engineering Applications; Cambridge University Press: Cambridge, UK, 2004.

35. Miller, A.J.; Cluer, B.L. Modeling considerations for simulation of flow in bedrock channels. In Rivers over Rock: Fluvial Processes in Bedrock Channels; Tinkler, K.J., Wohl, B.L., Eds.; Geophysical Monograph Series; American Geophysical Union: Washington, DC, USA, 2013; Volume 107, pp. 61-104.

36. Large, W.G.; Pond, S. Open ocean momentum flux measurements in moderate to strong winds. J. Phys. Oceanogr. 1981, 11, 324-336. [CrossRef]

37. Powell, M.D.; Vickery, P.J.; Reinhold, T.A. Reduced drag coefficient for high wind speeds in tropical cyclones. Nature 2003, 422, 279-283. [CrossRef] [PubMed]

(C) 2017 by the authors. Licensee MDPI, Basel, Switzerland. This article is an open access article distributed under the terms and conditions of the Creative Commons Attribution (CC BY) license (http:/ / creativecommons.org/licenses/by/4.0/). 